\title{
Application of SeDeM expert systems in preformulation studies of pediatric ibuprofen ODT tablets
}

EMESE SIPOS ${ }^{1}$

ANDREA RAMONA OLTEAN ${ }^{1}$

ZOLTÁN-ISTVÁN SZABÓ ${ }^{1}$

EMÓKE-MARGIT RÉDAI ${ }^{2 *}$

GABRIELLA DÓNÁTH NAGY ${ }^{3}$

${ }^{1}$ Department of Drugs Industry and Pharmaceutical Management Faculty of Pharmacy, University of Medicine and Pharmacy Tirgu Mureş 540139 Targu Mures, Romania

${ }^{2}$ Department of Pharmaceutical Technology, Faculty of Pharmacy University of Medicine and Pharmacy Tirgu Mureş, 540139 Targu Mures Romania

${ }^{3}$ Department of Physical Chemistry Faculty of Pharmacy, University of Medicine and Pharmacy Tirgu Mureş 540139 Targu Mures, Romania

Accepted February 4, 2017

Published online March 8, 2017

\begin{abstract}
Pediatric, ibuprofen containing orodispersible tablets (ODTs) were prepared using the SeDeM expert system methodology. In order to facilitate formulation, directly compressible ibuprofen was employed (Ibuprofen DC $85^{\mathrm{TM}}$ ) and characterized using its SeDeM profile. The mannitol based superdisintegrant Ludiflash ${ }^{\circledR}$ was characterized by the SeDeM-ODT expert system, which also allowed calculation of the optimal excipient concentration in order to obtain suitable tablet hardness and disintegration time. After adding a sweetener and a standard combination of lubricants, the optimized formulation was directly compressed into tablets and evaluated in terms of tablet hardness, friability, disintegration time and dissolution profile. The SeDeM method was applied to determine the amount of corrective excipient (Ludiflash $^{\circledR}$ ) required for the compression of Ibuprofen DC $85^{\mathrm{TM}}$ in order to achieve suitable ODTs. Adequate tablet hardness, disintegration time, friability and dissolution profiles were found during tablet evaluation.
\end{abstract}

Keywords: Ibuprofen DC $85^{\mathrm{TM}}$, Ludiflash ${ }^{\circledR}$, orodispersible, SeDeM

Pediatric medication is specific from the point of view of pharmaceutical forms and in terms of active substances for this age group. In addition to specific pediatric therapy formulations such as suppositories, oral suspensions and soft capsules, new forms have been also described recently. ODTs are among these new forms. The European Pharmacopoeia (Ph. Eur.) defines ODTs as uncoated tablets intended to be placed in the mouth, where they disperse rapidly before being swallowed (1). In order to achieve rapid disintegration, the tablets need to be porous and possess adequate mechanic strength to ensure stability during storage or transport (2).

In the past decade, attention was focused on the development of ODTs by trying different solutions for improving formulation. Responding to this need, excipient manufac-

\footnotetext{
* Correspondence; e-mail: redai.emoke@umftgm.ro
} 
turers started marketing a number of so-called superdisintegrants that can be successfully used to achieve ODTs. On the other hand, many known techniques for preparing such pharmaceutical forms, such as lyophilization, freeze-drying, molding and direct compression techniques were also described $(2,3)$. Direct compression is a frequently used method to produce ODTs because it uses high efficiency tablet presses and a great variety of excipients. In this case, the most important step of ODT formulation consists of superdisintegrant selection and determination of its concentration (2).

In our particular case, Ludiflash ${ }^{\circledR}$ (a product developed by BASF) has been chosen as a superdisintegrant. One purpose of this study was to determine the amount of this excipient and the composition of a powder mixture suitable for direct compression in order to obtain ODTs.

Another important factor to consider is the suitability of the active pharmaceutical ingredient for direct compression. The SeDeM method has been applied to predict the suitability of the different excipients. Suñé et al. (4) described the preformulation methodology named the SeDeM Diagram expert system to characterize the active substances, excipients and powder blends in order to find if they have appropriate physicochemical properties to be directly compressed. Applying the method and using the formula proposed by Suñe et al. (5), it is possible to detect excipient properties that need improvement in order to enable direct compression as the method of manufacture.

Recent studies used SeDeM Diagrams to characterize a large number of disintegrants in order to verify their suitability for preparing ODTs by direct compression (6). It has also been shown that two newly introduced parameters, Index of Good Compressibility (IGC) and Index of Good Compressibility Bucodispersibility (IGCB), make it possible the calculate the quantity of superdisintegrant that enables both direct compressibility and suitable disintegration times (less than 3 minutes) $(7,8)$. Thus, SeDeM and SeDeM-ODT expert systems can save time and considerable financial resources in both preformulation and formulation phases $(9,10)$.

The aim of this study is the development of pediatric ODTs, prepared by direct compression, containing ibuprofen as an active substance. In 2011, Tayebi et al. described the formulation of $100 \mathrm{mg}$ ibuprofen ODTs obtained by granulation (11). Gryczke and his collaborators studied ibuprofen ODTs containing ibuprofen granules obtained by hot melt extrusion (12). A formulation study of ODTs containing $600 \mathrm{mg}$ ibuprofen using the SeDeM Expert system was presented by Aquliar-Díaz (7). The novelty of that study consists in the use of directly compressible formulation of the active substance (Ibuprofen DC $85^{\mathrm{TM}}$ ) and Ludiflash $^{\circledR}$, a direct compressible excipient designed for ODTs, based on co-processed mannitol. With the help of the SeDeM, or SeDeM-ODT, expert system, suitable formulations were found, which can be used to produce directly compressible pediatric ODTs.

\section{EXPERIMENTAL}

\section{Materials}

Ibuprofen DC $85^{\mathrm{TM}}$ was obtained from BASF, Germany. It is a co-processed mixture of ibuprofen ( $85.00 \%)$, microcrystalline cellulose (6.62 \%), colloidal silicon dioxide (5.43\%), croscarmellose sodium (5.43\%). Ludiflash ${ }^{\circledR}$, composed of mannitol (90\%), crospovidone 


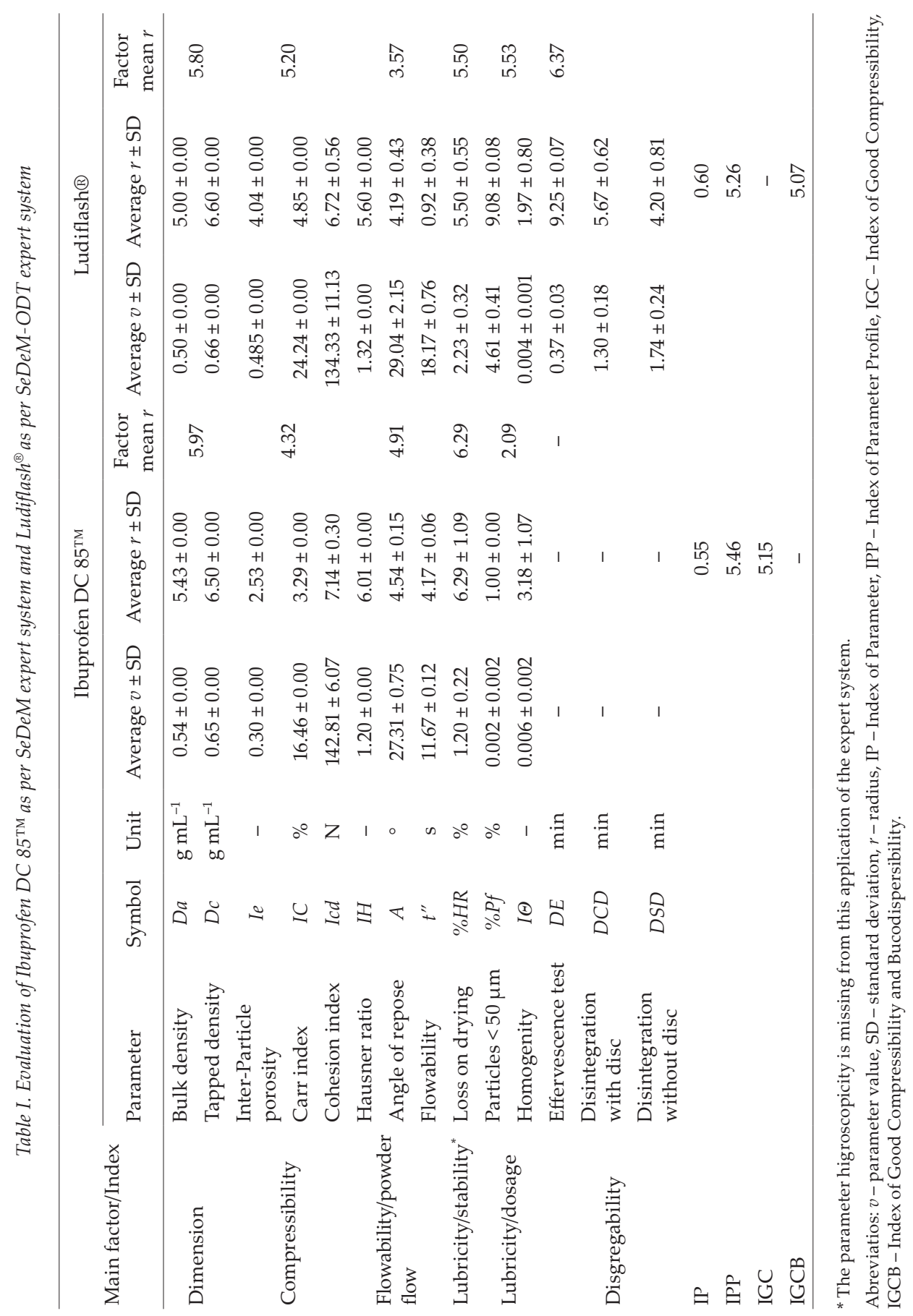


E. Sipos et al.: Application of SeDeM expert systems in preformulation studies of pediatric ibuprofen ODT tablets, Acta Pharm. 67 (2017) 237-246.

(5\%) and polyvinyl acetate (5\%) was also obtained from BASF, Germany. The other excipients used in this study were talc (Luzenac, Spain), Aerosil ${ }^{\circledR} 200$ (Evonik, Germany), magnesium stearate (Greven, Holland) and xylitol (Greven, Holland).

\section{Characterization of materials by the SeDeM and SeDeM-ODT methods}

Bulk and tapped densities. - Bulk density (Da) and tapped density (Dc) were calculated according to the method described in Section 2.9.34 of European Pharmacopoeia (Ph. Eur) (1).

Inter-particle porosity. - Inter-particle porosity (Ie) was calculated using the equation (1).

$$
I e=(D c-D a) /(D c \times D a)
$$
tion (2):

Carr index. - Carr index (IC \%) was calculated from Da and Dc according to the equa-

$$
I C=(D c-D a / D c) \times 100
$$

Cohesion index. - Cohesion index (Icd) was determined by compressing the powder in an eccentric press. The hardness $(\mathrm{N})$ of the obtained tablets was determined and mean hardness was calculated. First, raw powder was tested, but if it could not be compressed, $3.50 \%$ of the following mixture was added: talc $2.36 \%$, Aerosil ${ }^{\circledR} 2000.14 \%$ and magnesium stearate $1.00 \%$.

Hausner ratio. - Hausner ratio $(I H)$ was calculated from $D a$ and Dc according to the equation (3) (1):

$$
I H=D c / D a
$$

Angle of repose. - Angle of repose $(\alpha)$ was determined according to the official method described under section 2.9.36 of Ph. Eur. (1).

Flowability. - Flowability ( $\left.t^{\prime \prime}\right)$ is expressed in seconds and tenths of a second per 100 grams of sample, with the mean value of three measurements, as described in section 2.9.16 of Ph. Eur. (1).

Loss on drying. - Loss on drying $(H R)$ was determined according to the official method in Ph. Eur., described in section 2.2.32. (1).

Radius value. - Radius value was calculated depending on the obtained value range, if the values were between 0 and $2, r=\left(R_{\max } V\right) / V_{\max } ; R_{\max }$ is the radius top value $10, V_{\max }$ range top value $2 \mathrm{~V}$ - experimental data.

Particle size. - Percentage of particles measuring $<50 \mu \mathrm{m}(P \mathrm{f})$ was determined using the sieve test according to the general method described under section 2.9.12 of Ph. Eur. (1). The value returned was the percentage of particles that passed through a $0.05-\mathrm{mm}$ sieve. 
Homogeneity index. - Homogeneity index (IO) was determined according to the official method described in Ph. Eur. under section 2.9.12 (1). To determine particle size by means of the sieve test, the grain size of a $100 \mathrm{~g}$ sample was measured by subjecting a sieve stack to vibration for $10 \mathrm{~min}$ at speed 10 (CISA vibrator). Sieve sizes used were: $0.355 \mathrm{~mm}, 0.212$ $\mathrm{mm}, 0.100 \mathrm{~mm}$ and $0.050 \mathrm{~mm}$. The percentage of product retained in each sieve was calculated and the amount that passed through the $0.050 \mathrm{~mm}$ sieve was measured.

The equation (4) was applied to calculate the homogeneity index:

$$
I \theta=\frac{F_{\mathrm{m}}}{100+\left(d_{\mathrm{m}}-d_{\mathrm{m}-1}\right) F_{\mathrm{m}-1}+\left(d_{\mathrm{m}+1}-d_{\mathrm{m}}\right) F_{\mathrm{m}+1}+\left(d_{\mathrm{m}}-d_{\mathrm{m}-2}\right) F_{\mathrm{m}-2} \cdots+\left(d_{\mathrm{m}}-d_{\mathrm{m}+\mathrm{n}}\right) F_{\mathrm{m}-\mathrm{n}}+\left(d_{\mathrm{m}+\mathrm{n}}-d_{\mathrm{m}}\right) F_{\mathrm{m}+\mathrm{n}}}
$$

where $I \theta$ is homogeneity index, $F_{\mathrm{m}}$, percentage of particles in the majority range, $F_{\mathrm{m}-1}$, percentage of particles in the range immediately below the majority range, $F_{\mathrm{m}+1}$, percentage of particles in the range immediately above the majority range, $n$, order number of the fraction studied under a series, with respect to the major fraction, $d_{\mathrm{m}}$, mean diameter of particles in the major fraction, $d_{\mathrm{m}-1}$, mean diameter of particles in the fraction of the range immediately below the majority range and $d_{\mathrm{m}+1}$, mean diameter of particles in the fraction of the range immediately above the majority range.

Effervescence test. - Effervescence test (DE) was conducted according to the general monograph 701 of the United States Pharmacopeia (USP) $32^{\text {th }}$ ed. (13).

Disintegration. - Disintegration with disc (DCD) was carried out according to the general monograph 701 of USP (21) and section 2.9.1 of Ph. Eur. (1). Disintegration without disc (DSD) was determined according to the same monographs as DCD, the test being specific to ODTs.

\section{Design of ODT formulation}

Design of the ibuprofen containing pediatric ODT formulation was in accord with the sequence described by Aguilar-Díaz et al. for the SeDeM-ODT expert system (14): the active pharmaceutical ingredient (Ibuprofen DC $85^{\mathrm{TM}}$ ) was characterized by the SeDeM method. The co-processed excipient, containing the disintegrant $\left(\operatorname{Ludiflash}^{\circledR}\right)$, was evaluated by the SeDeM-ODT expert system, which, apart from the 5 main factors, contained an additional one, disgregability, based on three additional parameters. All experiments were carried out in triplicate for the parameters described in the tables. From the obtained parameter values $(v)$, different conversion factors were applied to convert these values to the corresponding radiuses $(r)$. SeDeM diagram was built on the basis of 11 parameters as an 11-sided polygon, while the polygon had 14 sides in the case of the SeDeM-ODT expert system.

To determine the suitability of Ibuprofen DC $85^{\mathrm{TM}}$ and Ludiflash ${ }^{\circledR}$ for direct compression, the following indices are calculated:

Index of parameter. - Index of parameter (IP), which is equal to the ratio between the number of parameter values equal to or greater than 5 and the total number of parameters.

$$
I P=\frac{\text { No.p } \geq 5}{\text { No.Pt }}
$$


where No. $\mathrm{p} \geq 5$ indicates the number of parameters with values equal to or higher than 5 and No. Pt indicates the total number of parameters studied. Acceptability limit corresponds to a score of 0.5 .

Index of parameter profile. - Index of parameter profile (IPP), which is the average $r$ value of all parameters. The acceptable limit corresponds to a score of 5 .

Index of good compressibility. - Index of good compressibility (IGC) is calculated by the equation (5):

$$
I G C=I P P \times f
$$

where $f$ is a reliability factor and is calculated from the SeDeM diagram as follows $f=$ polygon area/circle area. The acceptance limit should correspond to IGC $\geq 5$.

Index of good compressibility and bucodispersibility. - Index of good compressibility and bucodispersibility (IGCB) is calculated in the same manner as IGC, only in this case, the SeDeM-ODT diagram is used. The acceptance limit should correspond to IGCB $\geq 5$.

\section{Formulation of ibuprofen $100 \mathrm{mg}$ ODT tablets}

Using the equation proposed by Suñe et al. (6), the corrective concentration of Ludiflash ${ }^{\circledR}$ necessary to compress the active substance was calculated according the equation (6):

$$
C P=100-\left(\frac{R E-R}{R E-R P} \times 100\right)
$$

where $C P$ is percentage of corrective excipient, $R E$ mean-incidence radius value (compressibility) of the corrective excipient, $R$ is a mean-incidence radius value to be obtained in the blend and RP a mean-incidence radius value (compressibility) of the active substance. In general, $R=5$ value is recommended to achieve good compression. Once the unknown values in this equation have been replaced with the calculated values required for each substance to obtain $R=5$, the percentage of excipient recommended by the expert system to obtain an ODT tablet can be calculated. The calculated percentage of excipient was added to the standardized formula of lubricants described by Aguilar-Díaz et al. (14): talc $2.36 \%$, Aerosil ${ }^{\circledR} 2000.14 \%$ and magnesium stearate $1.00 \%$, totaling $3.5 \%$ of lubricants. The remaining percentage corresponded to the active pharmaceutical ingredient and the sweetener.

All prime materials used for the preparation of the pharmaceutical form were weighed and mixed using an Erweka AR 402 mixer (Erweka, Germany) for 3 minutes at a rotation speed of $50 \mathrm{rpm}$. Thereafter, powder mixtures were compressed with a continuous rotary press (RIVA Piccola, Argentina), using $12 \mathrm{~mm}$ punches and a compression force of $4.8 \mathrm{kN}$.

\section{Characterization of ODT tablets}

Disintegration test. - The test was elaborated according to the official USP method (general monograph 701), with and without disk with the Pharmatest PTZ equipment, using 6 tablets (13). 
Tablet hardness. - The test was elaborated according to section 2.9.8 of Ph. Eur. (1) using Pharmatest PTB 411 equipment, employing 10 tablets.

Friability. - The test was elaborated according to section 2.9.8 of Ph. Eur. (1) using Pharmatest PTF E.

Dissolution profile. - The test was elaborated according to USP methodology, on an Erweka DT 80 dissolution tester (Gemany), using the rotating paddle method (Apparatus 2), operated for 30 minutes, at $50 \mathrm{rpm}$ rotation speed, under the following conditions: 900 $\mathrm{mL}$ dissolution media $\mathrm{pH} 7.2$, temperature: $37 \pm 0.5{ }^{\circ} \mathrm{C}$ (13). Samples were withdrawn at 1 , $2,3,4,5,15,30,60$ minutes and filtered. The withdrawn sample volume was replaced with an equal volume of preheated dissolution medium. Dissolved content of the active substance was determined using a spectrophotometer (UV-1601PC, Shimadzu, Japan) at $220 \mathrm{~nm}$.

\section{RESULTS AND DISCUSSION}

Ibuprofen DC $85^{\mathrm{TM}}$ was characterized according to the SeDeM expert system. The justification for not using SeDeM-ODT is that the API was not expected to have disgregability properties, these being conferred by the disintegrant used in the formulation. However, the compressibility of the active substance still needed to be evaluated. The mean parameter values $(v)$ and standard deviations were calculated from the data obtained during the evaluation and were transformed in radii $(r)$; mean $r$ values were also calculated individually for the five factors (Table I). Based on these data, the SeDeM diagram was constructed for the prime material (Fig. 1).

Ibuprofen DC $85^{\mathrm{TM}}$ proved to have adequate dimensional characteristics (mean $r$ value 5.97), good lubricity/stability (mean $r$ value 6.29) and borderline acceptable flowability/ powder flow (mean $r$ value 4.91). Lubricity/dosage had the lowest mean $r$ value (2.09). This is mainly due to the high active substance ratio and larger particle size of the prime material (85\% ibuprofen), but it can be further improved by adding lubricant. Mean $r$ value for compressibility was also below 5; however, the co-processed API showed a high cohesion index ( $r$ value 7.14), yielding tablets with high tensile strength. When compared to the re-

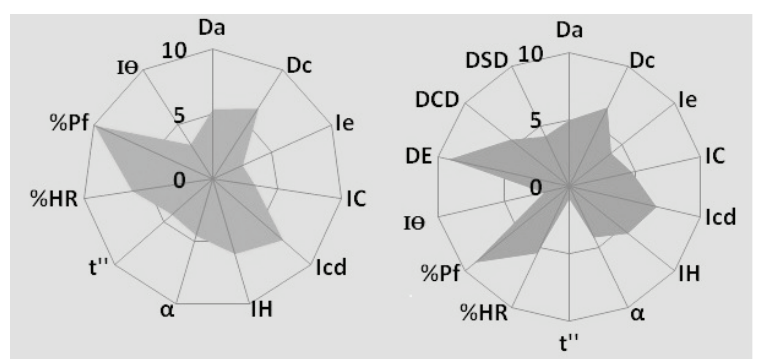

$D a$ - bulk density, $D c$ - tapped density, Ie - inter-particle porosity, IC - Carr index, Icd - cohesion index, IH - Hausner ratio, $\alpha$ - angle of repose, $t^{\prime \prime}-$ flowability, $H R$ - loss on drying, $P f$ - percentage of particles measuring $<50 \mu \mathrm{m}$, $I \Theta$ - homogenity index, $D E$ - effervescence test, $D C D$ - disintegration with disc, $D S D$ - disintegration without disc

Fig. 1. The SeDeM diagram for Ibuprofen DC $85^{\mathrm{TM}}$ (on the left) and the SeDeM-ODT diagram for Ludiflash $^{\circledR}$ (on the right). 
sults from the literature, obtained for bulk ibuprofen (15), the direct compressible Ibuprofen DC $85^{\mathrm{TM}}$ proved to have better flowability. It is also non-sticking and was found suitable for direct compression.

The co-processed, mannitol based excipient Ludiflash ${ }^{\circledR}$ was characterized by the SeDeM-ODT expert system, which takes advantage of introducing a sixth factor (disgregability), in addition to the five factors described in the "traditional" SeDeM expert system. Based on the knowledge gained by applying the SeDeM-ODT expert system, one can predict the suitability of an excipient or powder blend to produce ODTs, employing direct compression. The results obtained for Ludiflash ${ }^{\circledR}$ are given in Table I, while the SeDeMODT diagram is shown in Fig. 1.

To determine whether the prime materials are suitable for direct compression, parametric $(I P)$, parametric profile (IPP), good compressibility (IGC) and good compressibility bucodispersibility (IGCB) indexes were calculated based on the SeDeM Diagrams (Table I). All indexes for both excipients were above the threshold limit values. The results obtained in the case of Ludiflash ${ }^{\circledR}$ indicated $\mathrm{r}$ values below 5 for inter-particle porosity, Carr index, angle of repose, flowability, homogeneity and disintegration without disc. However, mean $r$ values were all above 5, except for flowability/powder flow. Like in the case of Ibuprofen DC $85^{\mathrm{TM}}$, addition of lubricants is expected to improve flowability of this excipient. The results obtained for the additionally introduced parameter, disgregability, indicate excellent disintegration properties for the excipient. The apparent anomaly in the case of disintegration without disk (i.e., individual $r$ value below 5) can be explained by the comparatively high compression force $(13 \mathrm{kN})$ that had to be applied in order to achieve tablets with acceptable mechanical strength. Still, disintegration times were well within the stipulated limit of 3 minutes.

The SeDeM method was applied to determine the amount of corrective excipient (Ludiflash ${ }^{\circledR}$ ) required for compression of Ibuprofen DC $85^{\mathrm{TM}}$ in order to achieve suitable ODTs. Each tablet contains 19.27 \% Ibuprofen DC 85 concentration of lubricants was added as proposed by Aguilar-Díaz et al. (14): talc $2.36 \%$, Aerosil $^{\circledR} 2000.14 \%$ and magnesium stearate $1.00 \%$. Ibuprofen has a bitter taste, so xylitol $(0.1 \%)$ was chosen as sweetener. Table II shows evaluation results of the developed ibuprofen ODT.

As the amount of Ludiflash ${ }^{\circledR}$ is high, low tablet hardness is expected with the low compression force applied. In our case, however, adequate mechanical strength was achieved, promising no difficulties during packaging. Moreover, the obtained friability was also well within the limits stipulated by Ph. Eur. and disintegration time of the optimized formulation also met Ph. Eur. stipulations.

Table II. Results of evaluations and acceptance limits for the developed ibuprofen ODT

\begin{tabular}{lcc}
\hline Test & Result & Acceptance limit \\
\hline Disintegration with disc (s) & $37 \pm 1$ & $\leq 180$ \\
Disintegration without disc (s) & $30 \pm 1$ & $\leq 180$ \\
Hardness (N) & $60.73 \pm 2.45$ & $\geq 30$ \\
Friability (\%) & $0.40 \pm 0.07$ & $\leq 1$ \\
\hline
\end{tabular}




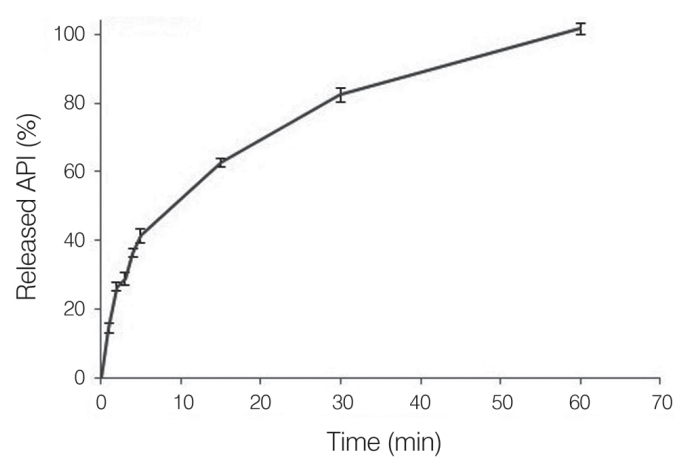

Fig. 2. Dissolution profile of ODT tablets (error bars represent standard deviation values).

Although not specific to ODTs, dissolution studies were also performed (Fig. 2). The developed formulation met the requirements of USP Ibuprofen Tablets Monograph (not less than $80 \%$ ibuprofen dissolved after 60 minutes).

\section{CONCLUSIONS}

A directly compressible form of ibuprofen (Ibuprofen DC $85^{\mathrm{TM}}$ ) and a mannitol based co-processed excipient, Ludiflash ${ }^{\circledR}$, were characterized using the SeDeM and SeDeM-ODT expert system, respectively. The established SeDeM profiles offered valuable information about the suitability of raw materials for direct compression, thus facilitating and accelerating preformulation studies. Based on the expert system, in order to achieve adequate disintegration time, the necessary concentration of superdisintegrant (Ludiflash ${ }^{\circledR}$ ) was calculated. After the addition of a sweetener and a standard concentration of lubricants, the optimized formulation was compressed into tablets. The presented composition proved to be proper for direct compression and hence the obtained tablets were evaluated. Adequate tablet hardness, disintegration time, friability and dissolution profiles were found during tablet evaluation, pointing towards a proper dosage form that could be used in pediatric patients.

Acknowledgements. - This paper was published in the frame of European Social Fund, Human Resources Development Operational Programme 2007-2013, Project No. POSDRU/159/1.5/S/136893. SzZI thanks Collegium Talentum for financial support.

\section{REFERENCES}

1. European Pharmacopoeia, $8^{\text {th }}$ ed., Vol. 2, Council of Europe, 2014, Strasbourg, France.

2. A. K. Nayak and K. Manna, Current developments in orally disintegrating tablet technology, J. Pharm. Educ. Res. 2 (2011) 21-34.

3. A. Zajicek, M. J. Fossler, J. S. Barrett, J. H. Worthington, R. Ternik, G. Charkoftaki, S. Lum, J. Breitkreutz, M. Baltezor, P. Macheras, M. Khan, S. Agharkar and D. D. Maclaren, A report from the pediatric formulations task force: perspectives on the state of child-friendly oral dosage forms, The AAPS Journal 15 (2013) 1072-1081; DOI: 10.1208/s12248-013-9511-5. 
4. J. M. Suñé-Negre, M. Roig Carreras, R. Fuster García, C. Hernández Pérez et al., Nueva metodologia de preformulacion galenica para la caracterizacion de sustancias en relacion a su viabilidad para la compresion: diagrama SeDeM, Cienc. Tecnol. Pharm. 3 (2005) 125-136.

5. J. M. Suñé-Negre, P. Pérez Lozano, M. Miñarro, M. Roig, R. Fuster, C. Hernández, R. Ruhí, E. García-Montoya and J. R Ticó, Application of the SeDeM Diagram and new mathematical equation in the design of direct compression tablet formulation, Eur. J. Pharm. Biopharm. 69 (2008) 1029-1039; DOI: 10.1016/j.ejpb.2008.01.020.

6. J. E. Aguilar-Díaz, E. García-Montoya, P. Pérez-Lozano, J. M. Suñé-Negre, M. Suñe-Negre, M. Miñarro and J. R. Ticó, The use of the SeDeM Diagram expert system to determine the suitability of diluents-disintegrants for direct compression and their use in formulation of ODT, Eur. J. Pharm. Biopharm. 73 (2009) 414-423; DOI: 10.1016/j.ejpb.2009.07.001.

7. J. E. Aguilar-Díaz, E. García-Montoya, J. M. Sũné-Negre, P. Pérez-Lozano, M. Miñarro and J. R. Ticó, Predicting orally disintegrating tablets formulations of ibuprophen tablets: an application of the new SeDeM-ODT expert system, Eur. J. Pharm. Biopharm. 80 (2012) 638-648; DOI: 10.1016/j. ejpb.2011.12.012.

8. E. García Montoya, M. Suñé-Negre, P. Pérez Lozano, M. Miñarro Carmona and J. R. Ticó, Metodología de preformulación galénica para la caracterización de sustancias en relación a su viabilidad para la compresión: Diagrama SeDeM, Farmespaña Ind, enero-febrero (2010) 58-62.

9. M. Suñé-Negre, P. Pérez-Lozano, M. Roig, R. Fuster, Carmen Hernández, R. Ruhí, E. García-Montoya, M. Miñarro and J. R Ticó, Optimization of parameters of the SeDeM Diagram Expert System: Hausner index (IH) and relative humidity (\%RH), Eur. J. Pharm. Biopharm. 79 (2011) 464-472; DOI: 10.1016/j.ejpb.2011.04.002.

10. J. E. Aguilar-Díaz, E. García-Montoya, P. Pérez-Lozano, J. M. Suñé-Negre, M. Miñarro and J. R. Ticó, SeDeM expert system a new innovator tool to develop pharmaceutical forms, Drug Dev. Ind. Pharm. 40 (2014) 222-236; DOI: 10.3109/03639045.2012.756007.

11. H. Tayebi and S. A. Mortazavi, Formulation and Evaluation of a Novel Matrix-Type Orally Disintegrating Ibuprofen Tablet, Iran J. Pharm. Res. 10 (2011) 469-479.

12. A. Gryczke, S. Schminke, M. Maniruzzaman, J. Beck and D. Douroumis, Development and evaluation of orally disintegrating tablets (ODTs) containing Ibuprofen granules prepared by hot melt extrusion, Colloids Surf. B Biointerfaces 86 (2011) 275-284. DOI: 10.1016/j.colsurfb.2011.04.007.

13. United States Pharmacopeia, 32 ${ }^{\text {nd }}$ Revision, United States Pharmacopeia, 2009, Convention, Inc. Rockville (MD).

14. J. E. Aguilar, E. Garcia-Montoya, P. Perez-Lozano, J. M. Suñé-Negre, M. Carmona and J. Grau, Formulation Tools for Pharmaceutical Development, Woodhead Publishing, Philadelphia 2013, pp. 137-154.

15. L. X. Liu, I. Marziano, A. C. Bentham, J. D. Litster, E. T. White and T. Howes, Effect of particle properties on the flowability of ibuprofen powders, Int. J. Pharm. 362 (2008) 109-117; DOI: 10.1016/j. ijpharm.2008.06.023. 